\title{
Effects of chronic exposure to arsenate on the cardiovascular function of rats
}

\author{
M CARMIGNANI, ${ }^{1}$ P BOSCOLO, ${ }^{2}$ AND A IANNACCONE ${ }^{2 *}$ \\ From the Departments of Pharmacology ${ }^{1}$ and Occupational Medicine, ${ }^{2}$ Catholic University School of \\ Medicine, Rome, Italy
}

ABSTRACT Cardiovascular function was studied in anaesthetised male rats which received 50 $\mu \mathrm{g} / \mathrm{ml}$ of arsenic (as sodium arsenate) in deionised drinking water for 320 days. High urinary excretion of arsenic was found at the end of treatment and the metal accumulated considerably in the kidneys and liver, which both presented slight alterations. No histopathological modifications were evident in other organs. Base line blood pressure, cardiac inotropism, and chronotropism and cardiovascular reactivity to noradrenaline, acetylcholine, angiotensin II, bradykinin, histamine, and serotonin did not differ in exposed or in control animals. In the exposed group, however, there was potentiation of the effects of vascular beta-adrenoceptor stimulation and a reduction in the vascular responsiveness to angiotensin I. Chronic arsenic exposure did not affect the baroreflex sensitivity but was able to induce sympathetic hyperactivity or hypersensitivity, or both, possibly associated with an antivagal action. Our results might help to explain the cardiovascular alterations seen in people chronically exposed to high concentrations of arsenic.

Chronic arsenic exposure may induce alterations of the cardiovascular system, ranging from electrocardiographic changes to infarction ${ }^{1-3}$ and from arteriosclerosis, Raynaud's syndrome, and acrocyanosis to thromboangioitis obliterans and gangrene in the feet. ${ }^{4-7}$ Epidemiological investigations $^{89}$ suggest that occupational arsenic exposure increases the incidence of mortality from cardiovascular disease. The extent of the cardiovascular injuries seems to depend on the nature of exposure, subjects, geographical area, and level of metal intake. ${ }^{40-12}$ There is also general agreement that electrocardiographic changes (prolongation of the Q-T interval, abnormal T-waves, lengthening of the S-T segment) occur before the appearance of irreversible vascular and cardiac alterations (swelling and proliferation of the endothelium, thickening and hyalinisation of the wall, thrombosis of peripheral and coronary vessels). ${ }^{13-15}$ The mechanisms by which chronic arsenic exposure induces cardiovascular alterations are poorly understood, and little information is available regarding the cardiovascular effects of arsenic exposure on experimental animals, ${ }^{16}$ although it has been reported that cats receiving either arsenite or arsenate in their feed showed electrocardiographic changes. ${ }^{17}$ On the other hand, no impairment of the cardiovascular sys-

\footnotetext{
*Dr Iannaccone has since died.

Received 18 June 1982

Accepted 3 August 1982
}

tem was observed in rats chronically exposed to sodium arsenite, though a great accumulation of the metal was found in the kidneys and in the heart. ${ }^{18}$

In the present study, therefore, we investigated some mechanisms by which chronic exposure to sodium arsenate might affect the systemic haemodynamics or the cardiovascular reactivity or both to several physiological agonists.

\section{Material and method}

\section{GENERAL}

Twenty weanling male Sprague-Dawley rats, randomly divided into two groups, were fed a standard laboratory diet. One group of animals received 50 $\mu \mathrm{g} / \mathrm{ml}$ of arsenic (as sodium arsenate) in deionised drinking water for 320 days, while the other group was kept as a control. At the end of the treatment the rats were placed in metabolic cages for the collection of 24 hour urine samples. They were then anaesthetised with intraperitoneally injected sodium pentobarbital (40 mg/kg body weight, in $0.9 \%$ saline) in order to assess cardiovascular function. Afterwards, the rats were killed by bleeding and the organs were taken for histological examination and determination of arsenic concentration.

FUNCTIONAL STUDY OF THE CARDIOVASCULAR SYSTEM

Under pentobarbital anaesthesia, the trachea was 
cannulated and a polyethylene catheter (PE 20 tubing) was inserted into the right femoral vein for the administration of drugs. Aortic blood pressure was recorded continuously from the catheterised (PE 90 tubing) left femoral artery, using a P23Db Statham pressure transducer (Statham Medical Instruments, Los Angeles, CA) connected to a Beckman type RM Dynograph recorder (Beckman Instruments Inc, Shiller Park, IL). The femoral cannula contained sodium heparin (100 USP units/ml). Cardiac inotropism was evaluated by determining the maximum rate of rise of the left ventricular pressure $(\mathrm{dP} / \mathrm{dt} \max )$ from the pulsatile aortic blood pressure by means of a Biotronex BL 620 derivative computer (Biotronex Laboratories Inc, Kensington, MA) according to Crawford et al ${ }^{19}$ and to Davidson et al. ${ }^{20}$ The heart rate was obtained with a cardiotachometer coupler triggered by the R-peak of the electrocardiogram recorded from standard lead II. Heart rate, $\mathrm{dP} / \mathrm{dt}$ max, and ECG were continuously monitored on the same poligraph recorder. The animals were breathing spontaneously, and a stabilisation period of $\mathbf{3 0}$ minutes was observed after the accomplishment of the surgical procedures.

The experimental protocol included: $(a)$ evaluation of the cardiovascular parameters in basal conditions; $(b)$ occlusion of the common carotid arteries for 30 seconds $^{21}$; (c) intravenous injection of noradrenaline $(1 \mu \mathrm{g} / \mathrm{kg})$, adrenaline $(0.125,0.5$, and 1 $\mu \mathrm{g} / \mathrm{kg})$, acetylcholine $(1.25 \mu \mathrm{g} / \mathrm{kg})$, angiotensin I $(0.5 \mu \mathrm{g} / \mathrm{kg})$, angiotensin II $(0.5 \mu \mathrm{g} / \mathrm{kg})$, bradykinin $(1.5 \mu \mathrm{g} / \mathrm{kg})$, histamine $(5 \mu \mathrm{g} / \mathrm{kg})$, and serotonin (5 $\mu \mathrm{g} / \mathrm{kg}) ;(d)$ bilateral selective vagotomy carried out at the neck below the nodose ganglion; and $(e)$ intravenous injection of graduated doses of hexamethonium $(0.625,1.25$, and $2.5 \mathrm{mg} / \mathrm{kg})$. Each consecutive test was not performed until the parameters returned to the values preceding the bilateral carotid occlusion and remained stable. All doses were expressed as the free base and peak effects were considered for each assay. Drugs were dissolved in $0.9 \%$ saline and solutions were kept in glassstoppered tubes at $2^{\circ}-4^{\circ} \mathrm{C}$ and protected from light to prevent oxidation. The stability of the solutions was ascertained by the rat blood pressure assay. Solutions were injected in a volume of $25 \mu \mathrm{l}$ over a period of three seconds and flushed in with $50 \mu$ lof $0.9 \%$ saline. The administration of solvents caused insignificant changes in the cardiovascular parameters.

\section{DETERMINATION OF ARSENIC}

The arsenic content of 24 hour urines and of liver, kidney, brain, and gastrocnemius muscle were determined by atomic absorption spectrophotometry after wet acid digestion, using a pro- cedure similar to that described by Orheim and Bovee. ${ }^{22}$

\section{HISTOPATHOLOGICAL STUDY}

Samples were taken from liver, kidney, cardiac and gastrocnemius muscles, arteries (thoracic and abdominal aorta, common carotids and succlavians), lungs, brain, and sciatic nerves for examination by light microscopy. They were fixed in $10 \%$ formalin, dehydrated in a graduated series of alcohols, immersed in xylene, and embedded in paraffin. Sections were stained with haematoxylin and eosin, periodic acid-Schiff (PAS), Masson-green lighttrichrome, Perl's, or a modified methenamine silver technique.

\section{STATISTICS}

Analysis of variance was used for statistical evaluation of the data. ${ }^{23}$ Only a $p$ value of under 0.05 was considered to be significant.

\section{Results}

No significant differences in body weight and behaviour were shown in the rats during treatment. Some of the treated animals, however, showed partial loss of hair not related to cutaneous infections.

\section{FUNCTIONAL STUDY OF THE CARDIOVASCULAR SYSTEM}

The animals exposed to arsenic showed base-line blood pressure, $\mathrm{dP} / \mathrm{dt}$ max (table 1), and heart rate no different from those observed in the control group. Similarly, no difference was shown in the electrocardiographic patterns of both treated and untreated rats. Also the reactivity of the baroreflex arc, tested by bilateral carotid occlusion, did not change after chronic exposure to arsenic (table 1). The experiments performed to evaluate possible effects of the metal on the cardiovascular responsiveness to some neurohumoral agonists showed that chronic arsenic exposure did not influence the cardiovascular responses to noradrenaline, acetylcholine, angiotensin II, bradykinin, histamine, and serotonin. In arsenic exposed rats, however, the systolic hypertensive and the diastolic hypotensive responses to adrenaline were, respectively, reversed and increased when the amine was given at the dose of $0.125 \mu \mathrm{g} / \mathrm{kg}$ (known to be provided with prevalent beta-adrenoceptor stimulating effects) (fig). On the other hand, the pressor responses to 1 and 2 $\mu \mathrm{g} / \mathrm{kg}$ of adrenaline (depending on a predominant stimulation of the vascular alpha-adrenoceptors) were unchanged in the arsenic exposed animals. It should be pointed out that neither inotropic nor chronotropic responses to all doses of adrenaline 
Table 1 Maximal cardiovascular changes after bilateral carotid occlusion (BCO), vagotomy, or intravenous hexamethonium (under vagotomy) in control and arsenic exposed male rats*

\begin{tabular}{|c|c|c|c|c|c|c|}
\hline \multirow{4}{*}{$\begin{array}{l}\text { BCO } \\
\text { Vagotomy } \\
\text { Hexamethonium }(\mathrm{mg} / \mathrm{kg}) \text { : } \\
0.62 \\
1.25 \\
2.50\end{array}$} & \multicolumn{2}{|c|}{ Systolic blood pressure } & \multicolumn{2}{|c|}{ Diastolic blood pressure } & \multicolumn{2}{|l|}{$d P / d t \max \dagger$} \\
\hline & \multicolumn{2}{|c|}{$\begin{array}{c}\text { Control } \\
\mathrm{mm} \mathrm{Hg}\end{array}$} & \multicolumn{2}{|c|}{$\begin{array}{c}\text { Control } \\
\mathrm{mm} \mathrm{Hg}\end{array}$} & Control & $\begin{array}{l}\text { Exposed } \\
m \mathrm{Hg} / \mathrm{s}\end{array}$ \\
\hline & $\begin{array}{l}+37 \pm 6 \\
+8 \pm 1\end{array}$ & $\begin{array}{l}+41 \pm 8 \\
+10 \pm 2\end{array}$ & $\begin{array}{l}+29 \pm 4 \\
+\quad 6 \pm 0.5\end{array}$ & $\begin{array}{l}+27 \pm 6 \\
+12 \pm 2^{* * * *}\end{array}$ & $\begin{array}{l}+3011 \pm 510 \\
+\quad 708 \pm 226\end{array}$ & $\begin{array}{l}+2680 \pm 411 \\
+1418 \pm 321^{*}\end{array}$ \\
\hline & $\begin{array}{l}-23 \pm 4 \\
-31 \pm 3 \\
-44 \pm 2\end{array}$ & $\begin{array}{l}-27 \pm 5 \\
-48 \pm 2^{* *} \\
-64 \pm 9^{*}\end{array}$ & $\begin{array}{l}-22 \pm 4 \\
-28 \pm 3 \\
-34 \pm 2\end{array}$ & $\begin{array}{l}-19 \pm 2 \\
-25 \pm 2 \\
-37 \pm 5\end{array}$ & $\begin{array}{l}-987 \pm 203 \\
-1197 \pm 296 \\
-1998 \pm 590\end{array}$ & $\begin{array}{l}-1572 \pm 338 \\
-3683 \pm 483^{* *} \\
-4965 \pm 401^{* *}\end{array}$ \\
\hline Base line & $124 \pm 7$ & $134 \pm 3$ & $97 \pm 6$ & $102 \pm 5$ & $9369 \pm 798$ & $8024 \pm 883$ \\
\hline
\end{tabular}

$\dagger$ All values are means \pm SEM ( $n=10$ in both groups).

$\S \mathrm{dP} / \mathrm{dt} \max ,=$ Maximum rate of rise of the left ventricular pressure.

${ }^{*} p<0.05,{ }^{* *} p<0.01$ indicate significantly different from control.

differed in control and arsenic exposed rats. Systolic and diastolic blood pressure responses to angiotensin I were significantly reduced in the arsenic treated group, without any change of either $\mathrm{dP} / \mathrm{dt} \max$ or heart rate (fig).

Selective bilateral vagotomy carried out below the nodose ganglion caused, in the exposed rats, diastolic hypertension and an increase of cardiac inotropism which was significantly higher than in the control animals (table 1). Moreover, intravenous administration under vagotomy of the ganglioplegic drug hexamethonium in doses of 1.25 and $2.5 \mathrm{mg} / \mathrm{kg}$ induced a greater systolic hypotension in the treated rats and a greater decrease of cardiac inotropism. On the other hand, hexamethonium, in a dose of $0.625 \mathrm{mg} / \mathrm{kg}$, caused systodiastolic hypotension, bradycardia, and reduced cardiac inotropism not significantly different in the two groups of rats (table 1).

\section{DETERMINATION OF ARSENIC}

At the end of the experiment, urinary arsenic concentrations were $63.4 \pm 8.1 \mu \mathrm{g} / \mathrm{l}$ (mean \pm SEM) in the control group and $23274 \pm 2942 \mu \mathrm{g} / \mathrm{l}$ in the exposed animals. In the treated rats arsenic accumulated in the brain and in the muscles, but greater accumulation of the metal was found in the kidney and in the liver (table 2).

\section{HISTOPATHOLOGICAL STUDY}

No alterations were found in the myocardium or in the gastrocnemius muscle, in the arterial vessels, in the lungs, in the brain, and in the sciatic nerves. The
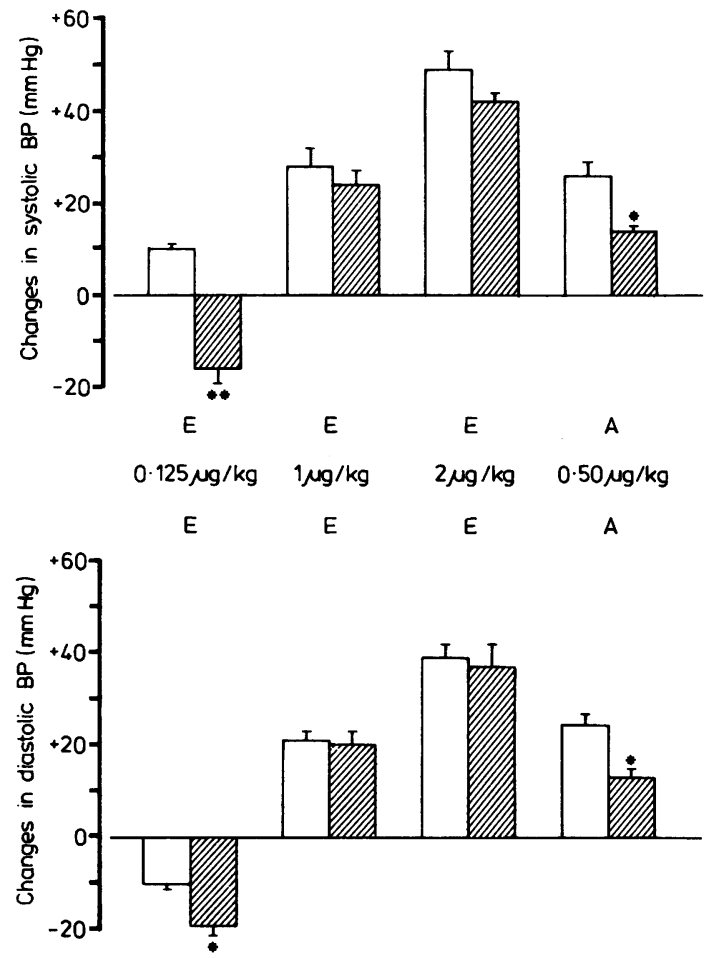

Maximal changes of systolic and diastolic blood pressure $(B P)$ after intravenous adrenaline $(E)$ and angiotensin $I(A)$ in control (open bars) and arsenic-exposed male rats (hatched bars). All values are means $\pm S E M(n=10$ in both groups). ${ }^{*} p<0.01$ and ${ }^{* *} p<0.001$ indicate significantly different from control.

Table 2 Arsenic content in different organs of arsenic-exposed male rats $\dagger$

\begin{tabular}{lccc}
\hline Groups & Liver $(\mu g / g)$ & Kidney $(\mu g / g)$ & Brain $(\mu g / g)$ \\
\hline Control & $0.26 \pm 0.01$ & $0.37 \pm 0.04$ & $0.06 \pm 0.01$ \\
Exposed & $25.23 \pm 7.45^{*}$ & $43.02 \pm 17.88^{*}$ & $5.12 \pm 0.93^{*}$ \\
\hline
\end{tabular}

tAll values are means \pm SEM $(n=10$ in both groups).

$\mathrm{p}<0.001$ indicate significantly different from control. 
liver of the exposed rats showed a normal lobular structure, but swollen hepatocytes were evident near the centrilobular veins. The kidneys of the treated rats showed glomerular and tubular alterations of a focal type. Glomerular capillaries were enlarged with the mesangial matrix thickened in small areas. Erythrocytes were evidenced in the tubular lumen, while haemosiderin granules were observed in the cytoplasm of epithelial cells of proximal tubules. Casts of amorphous hyaline material filled some tubules.

\section{Discussion}

In this study we exposed the animals to pentavalent arsenic, which is thought to be less toxic than the trivalent form, ${ }^{18}$ although trivalent arsenic may be transformed in vivo to pentavalent arsenic, ${ }^{24}$ and the inverse transformation is also thought to be possible. ${ }^{25}$

The high concentration of urinary arsenic found in the exposed rats confirms reports ${ }^{26}$ that inorganic arsenic is almost completely absorbed from the gastrointestinal tract. Our study also confirms that rats exposed to sodium arsenate accumulate arsenic in the tissues, by contrast with other laboratory animals and with man. ${ }^{27} 28$

The liver and kidneys were the only organs of the exposed rats to show histopathological lesions. The observed tubular damage may depend on the high urinary excretion of arsenic or on the competitive antagonism by which this element opposes the reabsorption of phosphate, or both. ${ }^{24} 29$ On the other hand, the glomerular lesions found in the exposed rats seem to emphasise a specific toxic action of arsenic on glomerular capillaries, since we did not observe alterations in the aorta or in other arteries. These glomerular lesions may also account for the erythrocytes and the haemosiderin granules which were observed in the tubular lumen and in the tubular epithelium respectively.

The absence of changes in the ECG, in the blood pressure, in cardiac inotropism and chronotropism, and the lack of histopathological alterations in the heart and in the arterial vessels of the exposed animals is in agreement with previous observations on rats chronically exposed to sodium arsenite. ${ }^{18}$ On the other hand, the cardiovascular responses observed in the exposed rats, after either vagotomy or administration of the higher doses of hexamethonium (given after vagotomy), appear to suggest a shift towards a sympathetic hypersensitivity or hyperactivity or both. The results obtained after vagotomy alone, however, do not exclude a possible antivagal action of the arsenic. The pressor, inotropic, and chronotropic responses to bilateral carotid occlusion did not differ in the two groups of rats so that it may be thought that the baroreflex mechanisms do not influence the cardiovascular reactivity to the sympathetic stimulation. Moreover, the cardiovascular reactivity to various physiological receptor agonists such as adrenaline, acetylcholine, angiotensin II, bradykinin, histamine, and serotonin) was not modified by the exposure. Conversely, the reversal of the slight systolic hypertension and the increase of the slight diastolic hypotension observed in the exposed rats after the administration of adrenaline in a dose of $0.125 \mu \mathrm{g} / \mathrm{kg}$ (known to have a prevalent action of beta-adrenoceptor stimulation) seem to emphasise a specific effect of arsenic in sensitising or in increasing, or both, the vascular reactivity to beta-adrenoceptor stimulation. A specific vascular tropism of arsenic appears to be confirmed by the reduced pressor responses to angiotensin I, not associated with changes of cardiac inotropism or chronotropism. Further experiments are therefore required to explain the mechanisms by which chronic arsenic exposure may affect the vascular responsiveness either to beta-adrenoceptor stimulation or to angiotensin $I$.

On the whole, our results show that chronic arsenic exposure may induce slight renal and hepatic lesions in rats, associated with some alterations of the vascular reactivity. The latter might precede and should be related to vascular and cardiac diseases observed in people chronically exposed to high levels of arsenic.

\section{References}

' Butzengeiger KH. Chronic arsenic poisoning I. EKG alterations and other cardiovascular manifestations. Deutsches Archiv für Klinische Medizin 1949;194:1-16.

2 Glazener FS, Ellis JG, Johnson PK. Electrocardiographic findings with arsenic poisoning. California Medicine 1968;109:158-62.

${ }^{3}$ Rosenberg HG. Systemic arterial disease with myocardial infarction. Report on two infants. Circulation 1973;47:270-4.

4 Borgono JM, Greiber R. Estudio epidemiologico del arsenicismo en la ciudad de Antofagasta. Revista Médica de Chile 1971;99:702-7.

s Tseng WP. Prognosis of blackfoot disease: A 10 year follow-up study. Journal of the Formosan Medical Association 1970;69:1-21.

- Moran S, Maturana G, Rosenberg H, Casanegra P, Dubernet J. Occlusions coronariennes liées a une intoxication arsenicale chronique. Arch Mal Coeur 1977;70:1115-20.

' Rosenberg HG. Systemic arterial disease and chronic arsenicism in infants. Archives of Pathology 1975;97:360-5.

- Lee AM, Fraumeni JF Jnr. Arsenic and respiratory cancer in man: an occupational study. J Natl Cancer Inst 1969;42:1045-52.

- Axelson O, Dahlgren E, Jansson CD, Rehulund SO. Arsenic exposure and mortality: a case-referent study from a Swedish copper smelter. Br J Ind Med 1978;35:8-15.

${ }^{10}$ Borgono JM, Greiber R. Epidemiological study of arsenicism in the city of Antofagasta. In: Hemphill DD, ed. Trace substances 
in enviromental health, $V$. Columbia: The Missouri State University Press, 1972.

" Pinto SS, Henderson V, Enterline PE. Mortality experience of arsenic-exposed workers. Arch Environ Health 1978;33:325-31.

${ }^{12}$ Kodaura Y, Ishinishi N, Kunitake E, Inamasu T, Nobutomo K. Subclinical signs of the exposure to arsenic in a copper refinery. In: Nordberg GF, ed. Effects and dose-response relationship of toxic metals. Amsterdam: Elsevier, 1976:464-70.

${ }^{13}$ Grobe VJ. Periphere Durchblutungsstörungen und Acrocyanose bie arsengeschädigten Moselwinzern. Berufsdermatosen 1976;24:78-84.

${ }^{14}$ Weinberg SL. The electrocardiogram in acute arsenic poisoning. Am Heart J 1960;60:971-5.

is Oira M, Aoyama H. Epidemiological studies on the Morinaga powdered milk poisoning incident. Japanese Journal of Hygiene 1973;27:500-31.

${ }^{16}$ Henke F, Lubarsch O. Pathologische Anatomie und Histologie der Vergiftungen. In: Henke F, Lubarsch O, eds. Handbuch der Speziellen Pathologischen Anatomie und Histologie: 10. Berlin: Springer, 1930.

17 Massman W, Opitz H. Experimentalle Untersuchungen uber Ekg-Vernderunger bei chronischer Arsenvergiftung. Zeitschrift für Kreislaufforschung 1954;43:704.

is Byron WR, Bierbower GW, Brouwer JB, Hansen WH. Pathologic changes in rats and dogs from two-year feeding of sodium arsenite or sodium arsenate. Toxicol Appl Pharmacol 1967;10:132-47.

19 Crawford WJ, Teamey RJ, Hawthorn EW. Increased myocardial contractility during the initial period of hypotension in dogs following renal artery constriction. Fed Proc 1973;32:351.

${ }^{20}$ Davidson DM, Covell JW, Mallock CI, Ross J Jnr. Factors influencing indices of left ventricle contractility in the conscious dog. Cardiovasc Res 1974;8:299-312.

21 Tadepalli AS, Mills E, Schanberg SM. Depression and enhancement of baroreceptor pressor response after intracerebroventricular injection of noradrenergic blocking agents: dependence on sopracollicular areas of the brain. Circ Res 1976;39:724-30.

${ }^{22}$ Orheim RM, Bovee HH. Atomic absorption determination of nanogram quantities of arsenic in biological media. Anal Chem 1974;46:921-2.

${ }^{23}$ Snedecor GW, Cochran WG. Statistical methods Ames: The Iowa State University Press, 1971:432-8.

24 Ginsburg JM. Renal mechanism for excretion and transformation of arsenic in dog. Am J Physiol 1965;208:832-40.

${ }^{25}$ US Environmental Protection Agency-National Technical Information Service. Ambient water quality criteria for arsenic. Springfield, Virginia: 1980.

${ }^{26}$ Charbonneau SM, Tam GKH, Bryce F, Zawidzka Z, Sandi E. Metabolism of orally administered inorganic arsenic in the dog. Toxicol Lett 1979;3:107-13.

${ }^{27}$ Schroeder HA, Kanisawa M, Frost DV, Mitchener M. Germanium, tin and arsenic in rats: effects on growth, survival, pathological lesions and life span. $J$ Nutr 1968;96:37-45.

${ }^{28}$ Pietra R, Sabbioni E, Marafante E. Comparative metallobiochemical studies on present environmental levels of arsenic in mammals. I. Neutron activation analysis of nanogram levels of arsenic in tissues of laboratory animals. Journal of Radioanalytical Chemistry 1981;62:41-52.

${ }^{29}$ Ginsburg JM, Lotspeich WD. Interrelations of arsenate and phosphate transport in the dog kidney. Am J Physiol 1963;205:707-14. 